\title{
Defect Analysis of Textiles Using Artificial Neural Network
}

\author{
Subrata Das ${ }^{1}{ }^{*}$, Amitabh Wahi ${ }^{2}$, Keerthika $S^{1}$ and Thulasiram $\mathbf{N}^{1}$ \\ ${ }^{1}$ Department of Fashion Technology, Bannari Amman Institute of Technology, India \\ ${ }^{2}$ Department of Information Technology, Bannari Amman Institute of Technology, India
}

Submission: December 3, 2019; Published: January 24, 2020

*Corresponding author: Subrata Das, Department of Fashion Technology, Bannari Amman Institute of Technology, Sathyamangalam, Erode District, Tamil Nadu 638401, India

\section{Abstract}

Textile defect detection by application of supervised neural network trained on back error propagation algorithm is presented in this paper. The detection process consists of two parts. First is the conversion of coloured image into RGB components and extraction of features from each colour components. In the second part feed forward, artificial neural network was trained and tested on features obtained above. The trained neural classifier was tested on test dataset. The value of $80 \%$ classification accuracy was obtained on test dataset

Keywords: RGB components; Coloured image; Features; MATLAB; Neural network

\section{Introduction}

Image processing techniques have been found increasingly useful in many areas such as object recognition, agriculture and fruit industries, defect detection and sorting algorithms, quality inspection in industries, etc. Human working manually on quality control systems faces problems of fatigue and tediousness and also it is time consuming. Hence computer vision-based system for this problem is a potential solution in this regard. In this paper two class pattern classification problem is considered for quality

control in textile industry. Artificial neural network were applied in many areas including object re-cognation [1,2], medicine [3], audio signal processing [4], face recognition [5], distinguishing between bicycles and motorcycles [6], detailed study of neural networks and image processing in [7-11]. A review on artificial neural networks application in image processing is presented in the literature [12]. The aim of the present work is to investigate the fabric defects using artificial neural network.

\section{Methodology}

The proposed system having two parts: Feature vectors from images and performance analysis of the features by neural classifier. Consider a coloured image of size PXP of woven fabric. The image is converted into R,G,B components of size $128 X 128$ each. Each image in R, G and B were divided into N non- overlapping equal parts. From each sub image feature values like mean and standard deviation were extracted and stored in [1xn] vector form. This process was repeated for all images of woven fabric with and without defects. The flow chart of the diagram is shown in (Figure 1).

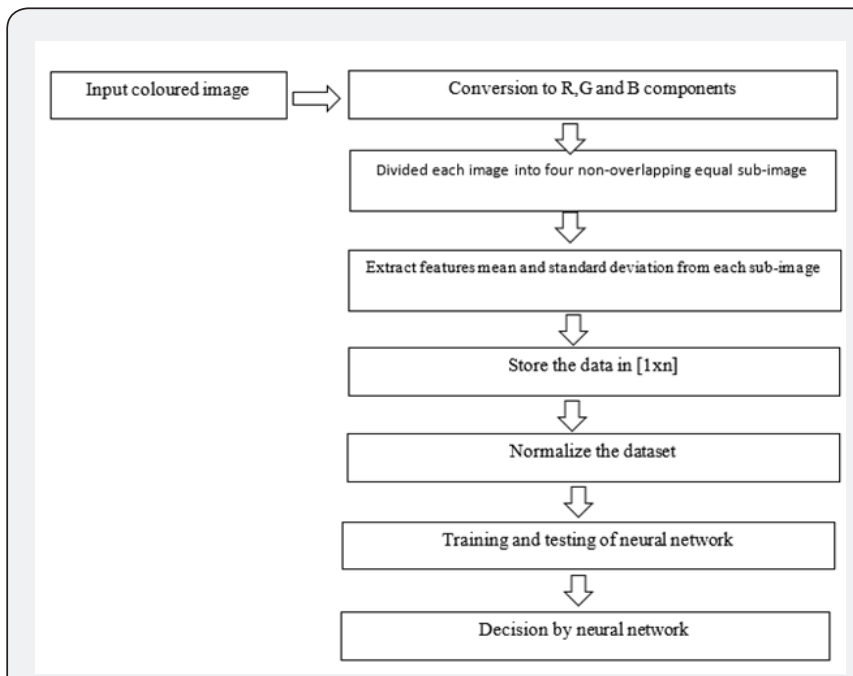

Figure 1: Diagram of Pall AriaTM Mobile PAM C60 Water Treatment System [23] a: Top view; b: Side view 


\section{Experiments}

The extracted features as mentioned above serve input to the neural classifier trained with gradient descend method. After successful completion of training neural classifier, the performance of the test dataset was evaluated by the coloured image of the woven fabric with and without defects was obtained by high resolution camera. Samples of defective fabrics are shown in (Figure 2). During the training process of the neural classifier, the weights of the classifier were initialized in between $( \pm 0.5)$. Two hidden layers for the neural classifier apart from input and output layer was considered. The Matlab software [13] was selected (Figure 3) for the work was carried out on Intel(R) core (TM) i7-7700HQ CPU @ 2.80GHZ, 8 GB RAM machine.
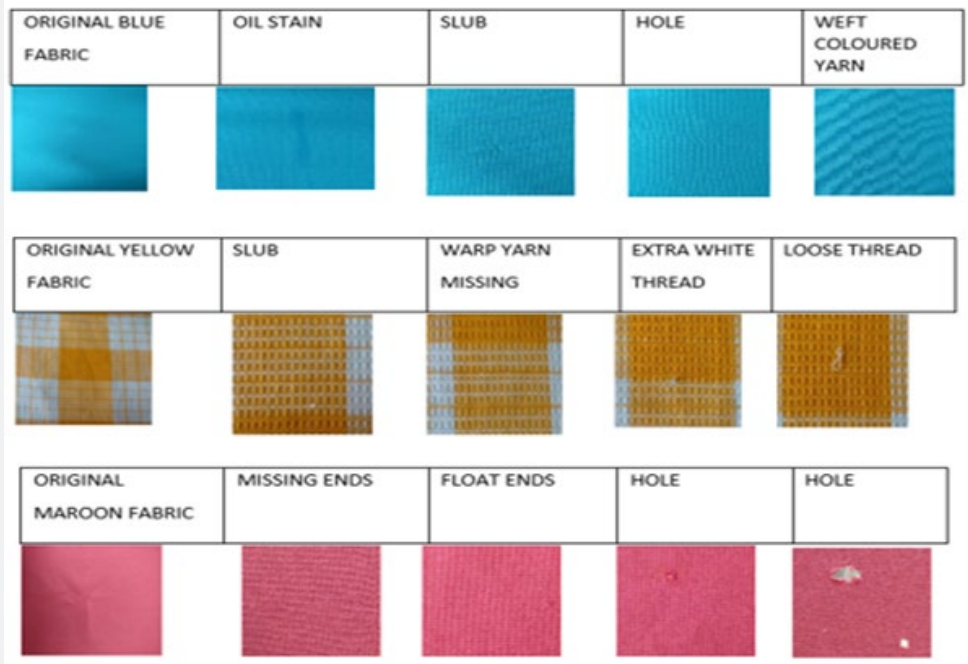

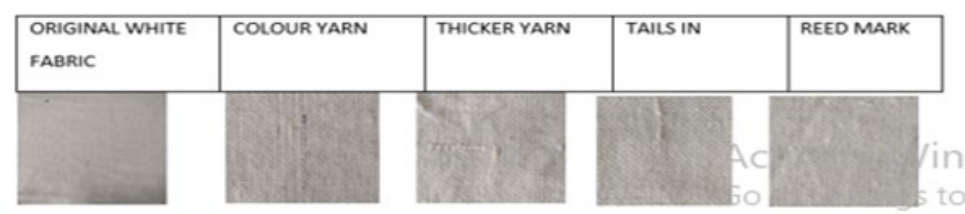

Figure 2: Samples of different fabrics

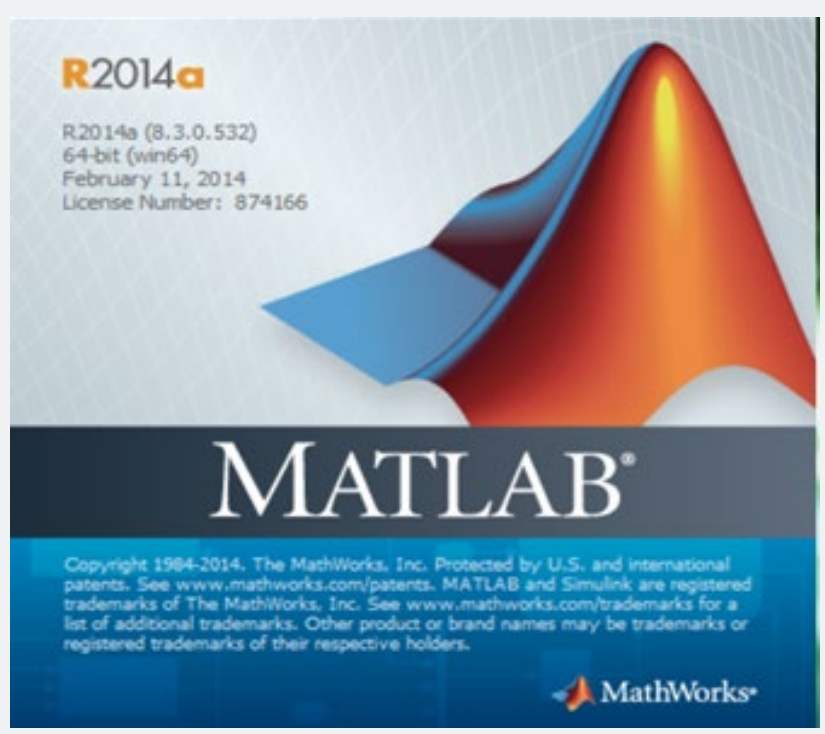

Figure 3: Software (Matlab). 


\section{Software Used: MATLAB}

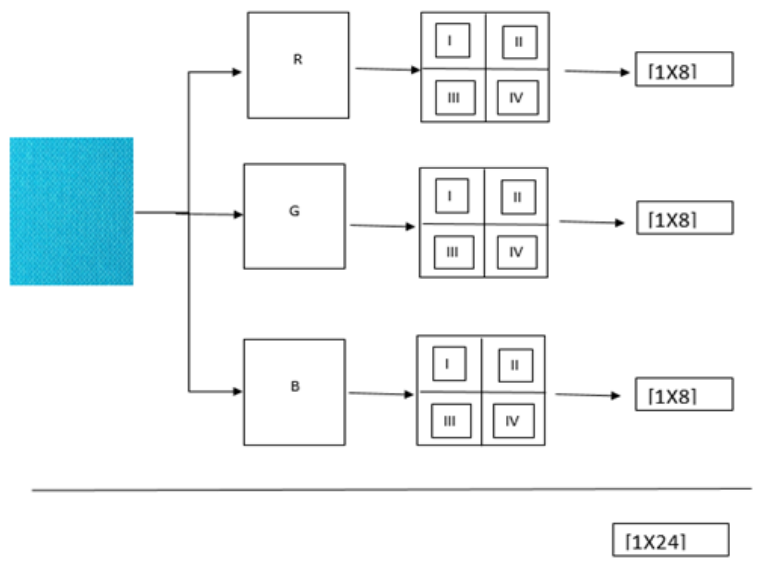

Figure 4: Dividing R,G and B components into sub-images and calculating features from each sub images.

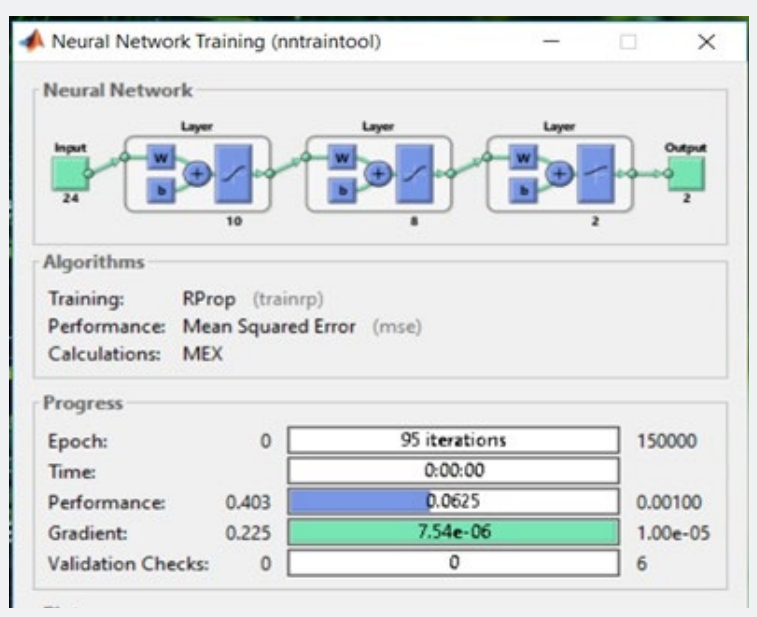

Figure 5: Neural Network Training.

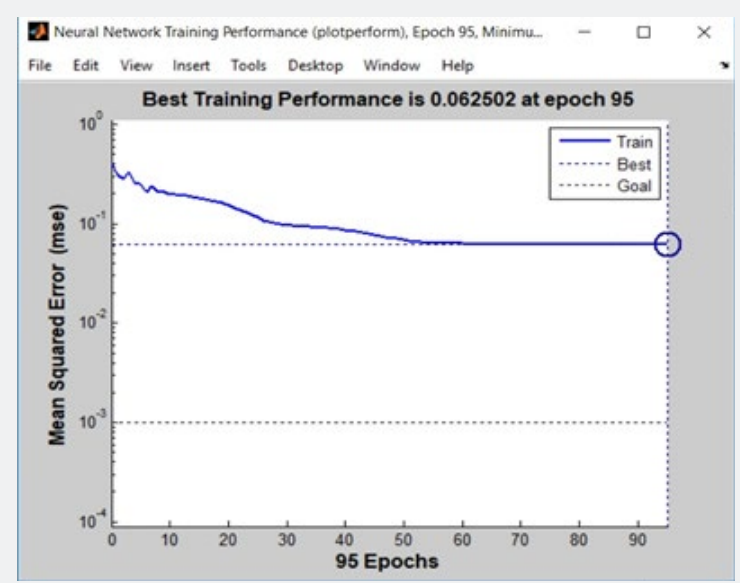

Figure 5: Training Performance. 
The coloured image of the woven fabric was captured and resized to $128 \times 128$. The image was converted into three components named as RBG respectively. Each component of RGB was divided into four equal non-overlapping sub-images as shown in (Figure 4). From each part of the sub-image mean and standard deviation was calculated and stored in a file [1X8] as feature vector. From the three parts [1X24] dimensional feature vector was obtained. The above method of feature extraction was repeated for all the images. A database of non-defective and defective woven fabric images with features were constituted. The neural network was trained with four different non-defective features dataset (Figure 5). After successful completion of neural network training, the performance of neural network was evaluated on defective woven database as shown in (Figure 6). $80 \%$ classification was achieved in test phase. The total number of 16 feature vectors as testing sample was presented to the neural network for performance evaluation. The neural network classifier mis-classified five patterns out of 16 test samples.

\section{Results \& Discussion}

A large number of experiments were carried out by trial and error methods to find the number of hidden layers and number of nodes to be present in the neural network structure. Finally, two hidden layers with optimised number of nodes were selected predicting the best results. The layers optimization of neural network was carried out on feature data sets during training phase. After layers and nodes optimization, the five training datasets with different training pattern not in test data sets were considered for the experiments. The neural network was trained properly on these data sets. The performance of the neural network was evaluated on the test datasets which was not in training datasets. The neural network program was run five times and output of the test phase was noted down. The mean of the correct prediction by neural network in test phase in five runs were calculated. The average of five cross validation result was considered and result was shown in Table 1. It was found that $80 \%$ performance was achieved on 16 test samples. Out of 16 patterns neural network classified 11 defective patterns correctly and 5 patterns were misclassified.

Table 1: Performance of neural classifier on woven fabrics dataset.

\begin{tabular}{|c|c|c|c|}
\hline Validation & Image Size & No of Features & \% defect detection \\
\hline $\begin{array}{c}\text { 5-cross } \\
\text { validation }\end{array}$ & $128 \times 128$ & 24 & 80 \\
\hline
\end{tabular}

\section{Conclusion}

A neural classification based woven fabric fault detection system was proposed. The system converts the coloured image into RGB components and extracts the features from the image database. There were four different classes of woven fabric and corresponding four defects of each class were considered as image dataset. From each image mean and standard deviation values were extracted from the pixels present. First, Neural network was trained successfully on these features and performance of the neural classifier was obtained on the test data. In future, more number of different defective samples may be obtained and other feature extraction methods (wavelets, grey level co-occurrence matrix) and classification methods (RBF neural network, kohonen networks, SVM) may be applied to compare the performance with the work proposed above.

\section{References}

1. Wenming Cao, Feng hao, Shoujue Wang (2004) The Application of RBF Neural Networks for Object Recognition. Information Sciences 55 pp.153-160.

2. Amitabh Wahi, Mohamed Athiq F, Palanisamy C (2008) Hybrid Feature Extraction Method-Based Object Recognition by Neural Network. In Proceedings of IEEE International Conference on Computing, Communication and Networking.

3. Mehmet Engin (2004) ECG Beat Classification Using Neuro- Fuzzy Network. Pattern Recognition Letters 25(15): 1751-1722.

4. Aurelio Uncini (2003) Audio Signal Processing by Neural Networks. Neurocomputing 55(3-4): 593-625.

5. Zeb J, Javed MY, Qayyum U (2007) Low Resolution Single Neural Network Based Face Recognition. IJBS 2(3): 206-210.

6. Stefano Messelodi, Carla Maria Modena and Gianni Cattoni (2007) Vision-based bicycle/motorcycle classification. Pattern Recognition Letters 28(13): 1719-1726.

7. Haykin S (1994) Neural Networks: A Comprehensive Foundation. In: $2^{\text {nd }}(\mathrm{edn}) .$, USA, pp: 1-823.

8. Bishop CM (1995) Neural Network for Pattern Recognition. In: Oxford University Press, UK, pp: 1-504.

9. Anil K Jain (1995) Fundamentals of Digital Image Processing. In: Prentice Hall of India Pvt Ltd, India.

10. Ashish Ghosh, Sankar K Pal (2002) Soft Computing Approach to Pattern Recognition and Image Processing. World Scientific, India, pp: 1-372.

11. Rafael C Gonzalez, Richard E Woods (2005) Digital Image Processing. In: $2^{\text {nd }}(e d n) .$, USA, pp: 1-793.

12. M Egmont Petersen, De Ridder D, Handels H (2002) Image Processing with Neural Networks-A Review. Pattern Recognition 35(10): 22792301.

13. H Denuth, H Mark (2002) The Matlab version 7.5: User guide. The Math Works Inc, USA. 
CC (i) This work is licensed under Creative (C) (i) Commons Attribution 4.0 Licens DOI: 10.19080/CTFTTE.2020.05.555677

\section{Your next submission with Juniper Publishers will reach you the below assets}

- Quality Editorial service

- Swift Peer Review

- Reprints availability

- E-prints Service

- Manuscript Podcast for convenient understanding

- Global attainment for your research

- Manuscript accessibility in different formats

( Pdf, E-pub, Full Text, Audio)

- Unceasing customer service

Track the below URL for one-step submission https://juniperpublishers.com/online-submission.php 